\title{
Reading Comprehension in a Second Language: The Role of Conjunctions*
}

Esther Geva

The purpose of this study was to examine whether and at what level of proficiency the meaning of conjunctions is comprehended by adult L2 learners, and whether and at what level of proficiency conjunctions facilitate integration of information in text. Subjects were sixty immigrant or foreign ESL students and thirty-six students whose first language was English. Subjects completed a series of tasks focussing on intrasentential, intersentential and discourse level comprehension of conjunctions. They also read three college level one-page texts, which could appear in one of three versions: normal-intact, implicit-all conjunctions omitted, and highlighted-all conjunctions printed in bold typeface. Each text was followed by a set of high- level comprehension questions focussing on logical relationships in these texts. Analyses have shown that a discourselevel measure of knowledge of conjunctions was more closely related to how L2 learners comprehend logical relationships in written discourse than were discrete, sentence level items. In addition, the more advanced ESL students were more capable of inferencing or using available logical relationships under the three text versions than were the intermediate ESL students. Finally, highlighting conjunctions had an adverse effect on intermediate level students and a facilitating effect on the advanced level students. The theoretical and practical implications of these results are discussed.

In written language conjunctions are used to signal the logical connections between ideas (Kintsch \& van Dijk, 1978). More specifically, conjunctions are used to mark discourse structure and the function of various text segments (Geva, 1983). Causal relations, for instance, are signalled by causal conjunctions (e.g. "since", "because", "due to"). The description of a process often includes temporal links such as "first", "next" and "then". When contrastive ideas are elaborated on, writers use adversative conjunctions (e.g. "however", "on the other hand"). Listlike elaborations of ideas may be marked by additive conjunctions such as "in addition", "likewise" and "furthermore". Examples are signalled by the additive conjunctions "for example" and "for

* The research reported in this paper was funded by a Social Sciences and Humanities Research Council of Canada Grant (No. 410-87-0108) to the author. The author is indebted to the staff and students at York University and the School of Continuing Education, University of Toronto, for their help and cooperation, and to the invaluable contributions of the research team members-Jane Appelt, Sonja Dennis and Roslyn Klaiman. 
instance". Finally, temporal conjunctions such as "in conclusion" and "to sum up" are typically used to signal conclusions.

There are suggestions in recent L2 literature that conjunctions may play an important role in discourse comprehension. In a preliminary study, Cohen and Fine (1978) found that non-native adult speakers of English do not sufficiently exploit cohesive textual links and fail therefore to comprehend adequately expository texts. Among examples given by Alexander (1980) to show the types of problems encountered by adult students reading scientific texts, is a case where a reader has misinterpreted the conjunction "since" as being temporal rather than causal. As a result, his translation of that text segment from English to German was faulty. Likewise, Swain (personal communication, 1982) has noticed that French-speaking medical students studying English in Quebec encountered problems in interpreting appropriately logical relations signalled by conjunctions such as "however", "moreover" and "therefore" in medical textbooks. Finally, a study by Sim and Bensoussan (1978) suggests that the comprehension of expository texts by university EFL (English as a Foreign Language) students may be affected by an incomplete mastery of function words as much as incomplete mastery of content words. The authors argue that tests of reading proficiency should therefore deal with comprehension of "the cohesive relationship between the components of a text, as well as understanding each component separately" (p. 40).

It is possible that L2 learners at a given level of proficiency can handle the logical meaning of conjunctions within a restricted syntactic context such as a single sentence, but may not be able to handle such relationships when conjunctions connect sentences or larger chunks of text. In other words it is possible to hypothesize a pyramid which describes the growing ability of $\mathbf{L} 2$ readers to use the logical meaning of conjunctions in text. Such a pyramid is portrayed in Figure 1. The base of the pyramid consists of basic, intrasentential comprehension of conjunctions. Less proficient learners may already have mastered this level. The next level consists of comprehension of conjunctions intersententially, followed by discourse level comprehension. Presumably, as the L2 learner gains more proficiency in the second language in general, and in reading in particular, he/she develops the ability to deal with larger chunks of text and with the logical meaning of conjunctions connecting such chunks.

In general then, it seems that interest in studying conjunctions in the context of reading expository texts by adult L2 learners deserves more attention than it has received so far. The purpose of this study was to examine whether and at what level of proficiency the meaning of conjunctions is comprehended by the L2 learner, and whether and at what level of proficiency they facilitate integration of information in text. 


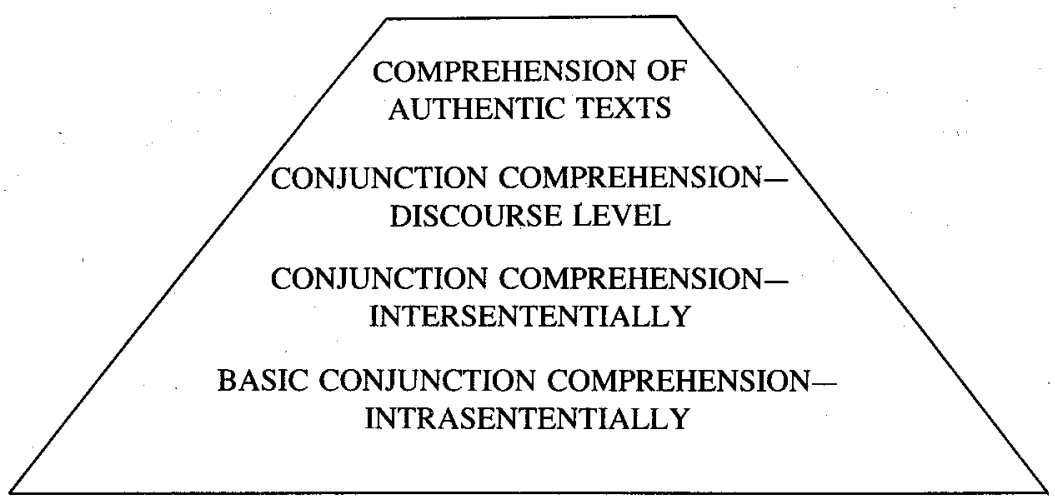

Figure 1. Level of L2 Proficiency.

The following research questions were addressed in the study:

1. Is there an effect for proficiency in English on conjunction comprehension?

2. Is there an effect for syntax (intrasentential vs. intersentential) on conjunction comprehension?

3. Do conjunctions facilitate the comprehension of technical prose?

4. Does the manner in which conjunctions are presented have an effect on comprehension of connected discourse?

5. Are conjunctions more facilitating at certain levels of L2 proficiency?

\section{SUBJECTS AND MATERIALS}

L2 subjects were 60 immigrant or foreign students in Ontario who were attending one of two Canadian universities, and were enrolled in courses designed to upgrade their English. None of the immigrant students had lived in Canada for more than 5 years. Control (L1) subjects were 36 students who were either born in Canada or who had lived in Canada for at least 6 years in an English-speaking environment. All subjects were first year students. The control subjects were approached in their "Introduction to Psychology" course.

\section{Student Background Variables}

Using a Foreign Service Institute (FSI) type instrument (Shohami, 1984), L2 teachers were asked to rate their students' oral proficiency on a 1-7 scale. This provided external information on how proficient these L2 students were in English. Clearly, this procedure could not be 
applied with the control subjects. However, information provided in the student background questionnaire (see below) enabled us to exclude from the control group subjects who were not highly proficient in English.

A student background questionnaire was filled out by all students participating in the study. It provided information about students' L1, agegroup, time in Canada, type of university courses they were taking, and use of English outside the English class (television, friends, family, novels and newspapers).

\section{Predictor Tasks}

In order to determine basic comprehension of conjunctions intrasententially subjects completed the "Fill in the Blank" task (FBT). The FBT (Geva \& Ryan, 1985a) consists of 30 multiple-choice items, 10 with "because", 10 with "although" and 10 with "if". In each sentence the clause following the conjunction has been omitted, and subjects have to choose the option that best completes the sentence. The options have been designed in such a way that one is grammatically appropriate but semantically inappropriate; another is semantically appropriate but grammatically inappropriate; a third option would have been correct had there been another conjunction in the sentence (e.g. "because" instead of "although"); the fourth option is correct both semantically and grammatically. The example below illustrates this task.

We could not see the man, although

a. he could have missed the car ride

b. we will have seen the car there

c. he was hidden behind a tree

d. we watched the old house.

Comprehension of the use of conjunctions intersententially was measured in a forced choice Sentence Continuation Task (SCT), illustrated below (see McClure \& Geva, 1983).

It was cold outside, although it was sunny.

a. So it was a good day for skiing.

b. So Johnny's mother made him wear a sweater.

It was sunny outside, but it was cold.

a. So Johnny's mother made him wear a sweater.

b. So it was a good day for skiing.

This task focuses on the conjunctions "but" and "although". Subjects have to decide for each of 30 items whether " $a$ " or " $b$ " should follow the first, two-clause, sentence. In this task one continuation semantically 
follows one of the clauses in the first sentence, while the second continuation follows the other clause. Since "but" is a coordinating conjunction, the continuation sentence should follow semantically the second clause. "Although", however, is a subordinating conjunction. Therefore, the continuation sentence should semantically follow the main clause. When "although" is in the middle of the sentence, the main clause precedes it, and the continuation sentence should therefore elaborate on the first clause. When "although" appears at the beginning of the sentence the main clause is second, and the continuation sentence should naturally elaborate on it. McClure and Geva (1983) have shown that highly literate and proficient speakers of English use this rule intuitively. We wanted to see whether adult L2 learners have extracted such a rule and whether they are sensitive to the more subtle implications of conjunction use beyond single sentence boundaries.

Discourse level knowledge of conjunctions was measured by means of a cloze test (see Geva, 1981). This test consists of two one-page, college level, expository texts from which all conjunctions have been omitted. Students had to choose the appropriate conjunctions out of sets of four suggested alternatives provided for each omitted conjunction.

\section{Dependent Variables}

To see whether conjunctions facilitate the comprehension of academic prose and whether the manner in which conjunctions are presented has an effect on comprehension of connected discourse, three college level one-page texts were selected ("Luther", "Pumps" and "Rockets"). Each of these texts could appear in one of three versions: normal-intact, implicit-all conjunctions omitted, and highlighted-all conjunctions printed in bold typeface (see Geva \& Ryan, 1985b for similar text manipulations). To control for text and order effects, version and text were counterbalanced. That is, all students read three different texts-one in each of the three versions. However, different students read different combinations of these texts. The completion of this Academic Text Comprehension (ATC) task involved reading one normal text, one implicit text and one highlighted text. Each text was followed by four multiple-choice, high-level comprehension questions focussing on logical relationships in the texts.

\section{Procedure}

Initially, all students were told that this was a study of how L2 university students comprehend college level texts. When data collection was completed, students were told that the study focussed specifically on conjunctions.

Data collection of L2 students extended over three sessions and was 
completed in three weeks. In the first session students filled the Student Background Questionnaire and the Fill in the Blank task (FBT). During the second session, L2 students completed the Sentence Completion Task (SCT) and the Cloze. The third session was devoted to the testing of the dependent measures. Data collection was done by the author and three graduate students.

The L1 control subjects were available only for one session. Consequently, it was impossible to give them all the tasks described in the Method section. Instead, they completed the Student Background Questionnaire, the Cloze and the Academic Text Comprehension (ATC) task.

\section{RESULTS AND DISCUSSION}

It is important to note that there were no relationships between any of the background variables (e.g. students' L1, age-group, time in Canada) and student performance on the linguistic and reading comprehension tasks. In other words, such variables as years in Canada and linguistic background were not systematically related to comprehension of logical relationships in texts.

Table 1

Intercorrelations between Oral Proficiency Ratings, Predictor Variables and Total Score on the Dependent Measure.

$$
\text { Oral }
$$

Proficiency

Oral

$\begin{array}{lrr}\text { Proficiency } & 1.00 & - \\ \text { FBT } & .37 & 1.00 \\ \text { SCT } & .24 & .43 \\ \text { Cloze } & .69 & .26 \\ \text { ATC } & & \end{array}$

(Total)
FBT

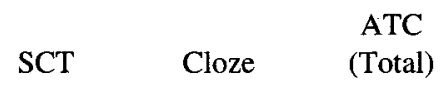

(Total)

The first research question asked in this study was whether proficiency in English is related to conjunction comprehension, or, stated otherwise, whether it is the case that with an increase in L2 proficiency, learners can more accurately complete various tasks which focus on conjunction comprehension. To answer this question the reader is referred to Table 1, which presents the intercorrelations among the various measures used in this study. Specifically, one can see that the oral proficiency ratings correlate positively and significantly with all but the 
SCT scores. That is, the higher one's oral proficiency rating, the higher one's scores tended to be on the other measures. One notes especially the high correlation $(r=.69)$ between oral proficiency rating and the cloze. This high correlation suggests that both of these measures tap perhaps a general L2 proficiency factor. In subsequent analysis (see below) the cloze scores were used to distinguish different levels of proficiency, since no oral proficiency ratings were available for L1 students and since performance on the cloze was seen as more closely related to reading expository college level tasks, than was oral proficiency.

The next research question focussed on the effect of syntax on conjunction comprehension. More specifically, the question is whether it is the case that one can handle conjunctions intrasententially and intersententially, but still be unable to handle logical relationships in authentic connected discourse. Furthermore, should one be able to handle conjunctions at a discourse level in order to be able to comprehend logical relationships in authentic texts?

Once again, Table 1 provides the answers to these questions. We note in Table 1 that, while the FBT and SCT correlate fairly highly with each other $(\mathrm{r}=.43$ ), the FBT (an intrasentential task) correlation with discourse level tasks (i.e. cloze and ATC) is much lower ( $\mathrm{r}=.26$ and $r=.27$, respectively). The SCT (an intersentential task) correlation with the cloze and the ATC is slightly higher $(r=.30$ and $r=.40$, respectively). At the same time the correlation between the cloze (a discourse level task) and the ATC is much higher $(r=.49)$. In other words, we see that a discourse level measure of knowledge of conjunctions is more closely related to how L2 learners comprehend logical relationships in discourse than are discrete, sentence level items. This conclusion is further supported by a factor analysis which indicated that the SCT and FBT have high loading on one factor, presumably measuring low level, syntactically restricted proficiency. The cloze and the ATC formed another, orthogonal, factor, presumably related to discourse level proficiency.

The section below addresses the last three research questions posed earlier-Do conjunctions facilitate reading comprehension? Does the manner in which conjunctions are presented have an effect on comprehension of connected discourse? And finally, are conjunctions more facilitating at more advanced levels of $\mathrm{L} 2$ proficiency than at low levels? The answer to these questions is based on a comparison of how native speakers of English as well as intermediate and advanced ESL learners were affected by the text manipulation described earlier (normal, implicit, highlighted).

First of all it should be noted that, on the whole, and as might be expected, native speakers of English had significantly higher scores than L2 learners on the overall ATC mean, as well as on each of the three 
separate text condition scores. This finding is graphically depicted in Figure 2. The reader will note that whether conjunctions were left intact in the text, omitted from the text or highlighted, native speakers of English were better able to handle these varying text conditions and task demands. They could more successfully infer logical relationships in the implicit condition, and use to their advantage the conjunctions available in the normal and highlighted conditions.

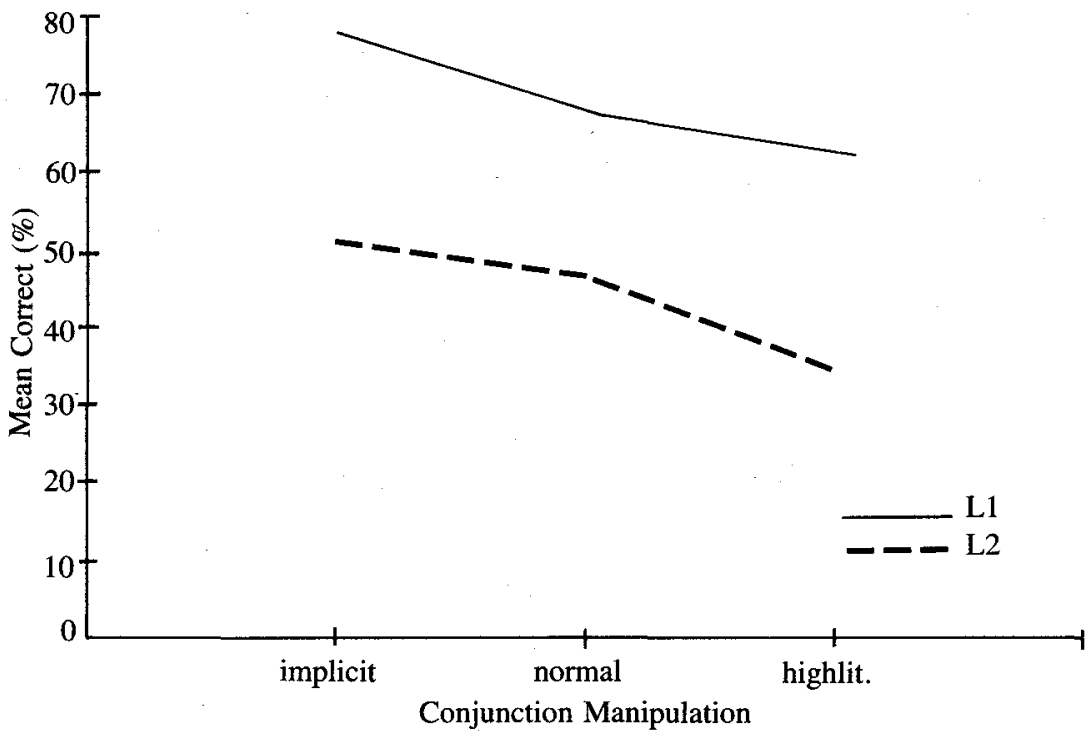

Figure 2. The effect of conjunction manipulation on comprehension by $L 1$ and L2 students.

Next we examine the way in which the different text conditions interacted with level of proficiency in English. Based on the finding that the conjunctions cloze test results correlated highly both with the oral proficiency ratings and with students' overall score on the ATC, the L2 sample was divided into intermediate and advanced levels. This was done by assigning to the intermediate group students whose cloze score was below the median and to the advanced group students whose cloze score was above the median.

As might be expected, the ATC overall mean score of native speakers of English was significantly higher than that of L2 learners. In addition, it was found that the manipulation of conjunctions in texts had a differential effect on intermediate and advanced L2 learners. To clarify these effects the reader is referred to Figure 3, which includes three profiles corresponding to the means on each of the three text conditions: implicit, normal and highlighted, in each of the three proficiency groups 
described above-namely, intermediate, advanced and native. In interpreting this figure it is possible to proceed both by making comparisons between proficiency groups and by examining within each group the effects of the various text conditions.

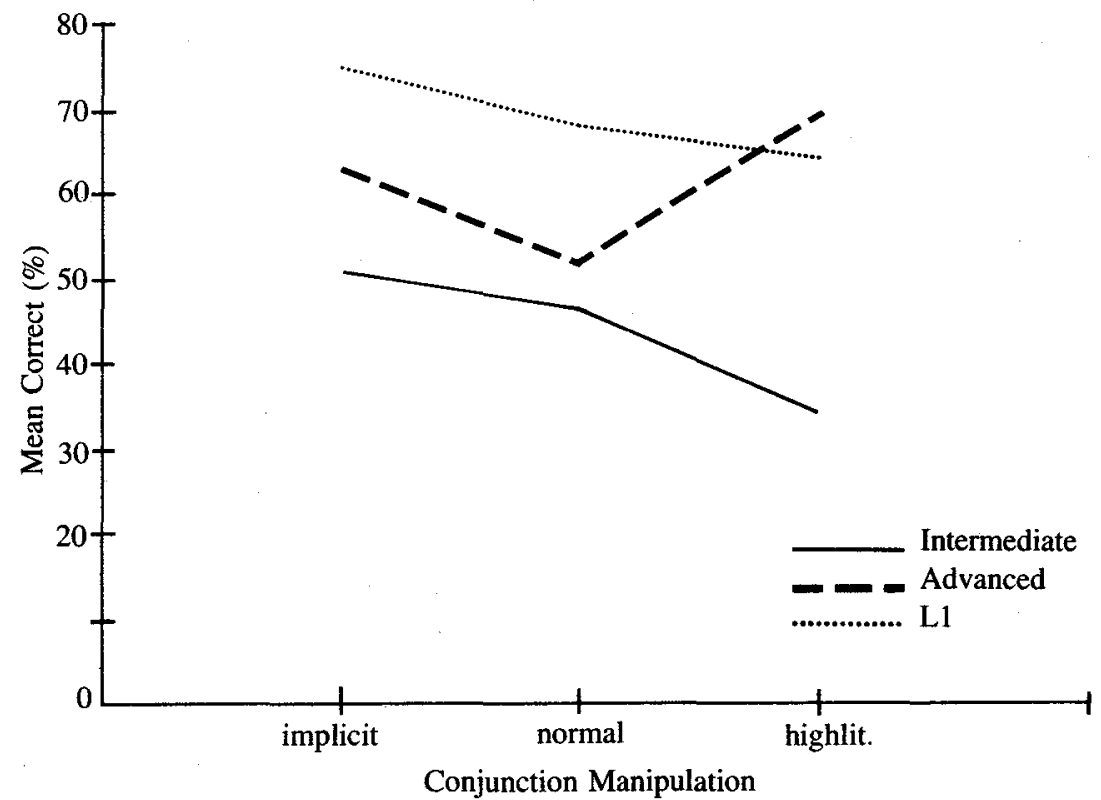

Figure 3. The effect of conjunction manipulation at varying levels of proficiency.

In addition to the L2-L1 significant differences referred to above, one notes that the profile of means on implicit, normal and highlighted texts in the advanced ESL group is higher than that in the intermediate group, and generally lower than the $\mathrm{Ll}$ group profile. That is, the more advanced ESL students were more capable of comprehending logical relationships under these varying texts conditions; they were more likely to infer relationships in the implicit condition, and to notice and use information signalled by conjunctions in the normal condition. The intermediate ESL students were less likely to infer implicit logical relationships than were the advanced students. Furthermore, they did not seem to actively perform "text connecting" when conjunctions were available.

With regard to the question of the differential effect of the three text manipulations and proficiency levels on comprehension, the information presented in Figure 3 is slightly more complicated (as reflected in a significant proficiency level by text condition interaction). When we look at the profile of native English speakers we see that there were 
negligible differences between the three text conditions. In other words, whether these students had to infer logical relationships in the implicit condition, notice and process naturally occurring conjunctions in the normal condition, or pay special attention to the conjunctions in the highlighted condition, the text condition means were not significantly different from each other. In general, the presence of conjunctions did not seem to be essential for facilitating text integration. Furthermore, the slightly higher mean in the implicit condition suggests that because of the absence of conjunctions students in fact read the implicit texts more carefully than in the explicit condition where they did not have to exercise such cognitive control (see Bialystok and Ryan, 1985). The picture is different in the intermediate and advanced groups. In particular one notes that contrary to what one might expect, the implicit condition, where students had to infer logical relationships, was not more difficult than the explicit condition, where conjunctions were already available. In fact, in the advanced L2 group, we note a similar trend to the one noted in the L1 group, with the mean in the implicit condition being somewhat higher than in the explicit condition. At the same time, while the differences between the intermediate and advanced group profiles are maintained, the results suggest that the presence or absence of conjunctions has had no effect on the intermediate students.

The most striking result is observed in the highlighted condition; highlighting conjunctions had an adverse effect on intermediate level students and a facilitating effect on the advanced level students, a difference that was highly significant. These results suggest that highlighting certain words in the text had a distracting effect on the less proficient L2 learners. Instead of using the highlighted conjunctions to perform "text connecting", the highlighted conjunctions have presumably distracted the less proficient L2 learners from attending to the text at a discourse level. On the other hand, the advanced L2 learners benefitted from the subtle textual suggestion to attend to the logical relationships between textual units. It is interesting to note that these results partially replicate those of a similar study conducted by Geva \& Ryan (1985b) with Grade 5 and 7 more skilled and less skilled L1 readers. In that study highlighting texts had a facilitating effect on all readers.

\section{CONCLUSIONS}

Results of the study suggest that conjunction manipulations in connected discourse have a differential effect on L2 learners with different levels of proficiency. Furthermore, low proficiency L2 students can handle logical relationships in limited contexts, as evidenced from their reasonable performance on the FBT and $\mathrm{SCT}$, and yet be unable to fully process logical relationships in extended discourse, as evidenced 
from their lower scores on the conjunctions cloze. When they read extended discourse they are less likely to infer logical relationships, and when conjunctions are present they are less likely to use them. The adverse effect of highlighting conjunctions on less proficient $L 2$ readers may be interpreted by using an information processing-limited capacity theory (see McLeod \& McLaughlin, in press). The intermediate students presumably spend most of their resources on attending to word meaning, sentence meaning and the gist of the text. By focussing on the highlighted conjunctions these subjects have had less available resources to attend to these other essential components of text processing.

Conversely, the advanced L2 learners have had more free cognitive resources to infer implicit logical relationships, and to notice and process explicit conjunctions. Highlighting conjunctions was especially beneficial for them because they were proficient enough in English, and directing their attention to conjunctions helped them to attend to text cohesion and coherence.

One of the practical implications of this study is that teaching ESL students to develop their skills in reading academic texts should involve, inter alia, specific practice with logical relationships at discourse level. Furthermore, it is unwise to assume that less advanced ESL learners will be able to automatically attend to explicitly signalled logical relationships or to easily infer logical relationships that are left implicit in expository texts, either because of writing style or for the sake of "text simplification". Finally, ESL teachers may wish to make use of the fact that the more advanced ESL learner, who is more likely to attend to conjunctions and to infer implicit logical relationships, can benefit from reading expository texts in which logical relationships are highlighted.

\section{REFERENCES}

Alexander, R. (1980). A learning to learn perspective on reading in a foreign language. Systems, 8, 113-119.

Bialystok, E. \& Ryan, E.B. (1985). Toward a definition of metalinguistic skills. Merrill-Palmer Quarterly, 31(3) 251-264.

Cohen, A.D. \& Fine, J. (1978). Reading history in English: Discourse analyses and the experience of native and non-native readers. Working Papers on Bilingualism, 16.

Geva, E. (1981). Meta-textual Notions and Reading Comprehension. Unpublished doctoral dissertation, University of Toronto.

Geva, E. (1983). Facilitating reading comprehension through flowcharting. Reading Research Quarterly, 18(4), 387-405.

Geva E. \& Ryan, E.B. (1985a). Working memory and linguistic proficiency in bilingual children. Manuscript in preparation.

Geva, E. \& Ryan, E.B. (1985b). Use of conjunctions in expository texts by 
skilled and less-skilled readers. Journal of Reading Behaviour, 17(4), 331346.

Kintsch, W. \& Van Dijk, T.A. (1978). Toward a model of text comprehension and production. Psychological Review, 85, 363-394.

McClure, E. \& Geva, E. (1983). The development of the cohesive use of adversative conjunctions in discourse. Discourse Processes, 6(4), 411-432.

McLeod, B. \& McLaughlin, B. (1986). Restructuring or automaticity? reading in a second language. Language Learning, 36, in press.

Shohami, E. (1984). Toward a valid and reliable measure of oral proficiency: From research results to educational policy. Manuscript.

Sim, D. \& Ben-Soussan, M. (1979). Control of contextualized function and content words as it affects EFL reading comprehension test scores. In Mackay, R., Barkman, B. \& Jordan, R.R. (Eds.). Reading in a Second Language: Hypotheses, Organization and Practices. Newbury House.

\section{THE AUTHOR}

Esther Geva, Ph.D. was raised in Israel, where she obtained her undergraduate and M.A. degrees in psychology, as well as an EFL teaching certificate. She is a graduate of the educational psychology program at O.I.S.E. and is currently a Research Associate at the Modern Language Centre and an Associate Member of the Center for Applied Cognitive Science at O.I.S.E. She is involved in research into issues in first and second language acquisition, the development of reading proficiency in $\mathrm{Ll}$ and $\mathrm{L} 2$, language testing, program evalution and the relationships between cognitive development and programming skills. Recently she taught an undergraduate course on L2 learning and a graduate course on research on reading in $\mathrm{L} 2$. 